\title{
Seroprevalence and risk factors of hepatitis $B$ virus among blood donors in district Charsadda Khyber Pakhtunkhwa Pakistan
}

\author{
Muhammad Israr ${ }^{1 *}$, Fawad Ali $^{2}$, Murtala Muhammad ${ }^{1}$ and Noor \\ Bahadar $^{3}$ \\ 1. College of life science, Hebei Normal University Shijiazhuang, Hebei PR-China \\ 2. ICS, University of Peshawar, Peshawar, KP-Pakistan \\ 3. School of Life Sciences, Northeast Normal University Changchun, Jilin PR-China \\ *Corresponding author's email: israrchemist88@gmail.com
}

Citation

Muhammad Israr, Fawad Ali, Murtala Muhammad and Noor Bahadar.Seroprevalence and risk factors of hepatitis B virus among blood donors in district Charsadda Khyber Pakhtunkhwa Pakistan. Pure and Applied Biology. Vol. 6, Issue 2, pp669-675. http://dx.doi.org/10.19045/bspab.2017.60070

Received: 02/02/2017 $\quad$ Revised: 08/05/2017 $\quad$ Accepted: 18/05/2017

Online First: 23/05/2017

\section{Abstract}

Hepatitis B Virus (HBV) is a serious worldwide public health issue both in underdeveloped and developed countries. About two billion individuals were infected by HBV globally, of which 400 million were chronic HBV carrier. The aim of this retrospective study was to investigate the seroprevalence and some possible risk factors of hepatitis B virus infection among male blood donors in district Charsadda, Khyber Pakhtunkhwa Pakistan. A total of 460 male blood donors with age range 15-55 years were screened for HBsAg by Immunochromatographic technique (ICT) and $3^{\text {rd }}$ generation enzyme-linked immunosorbent assay (ELISA). Out of 460 samples, $11(2.39 \%)$ were found positive for HBsAg by ICT, and 13(2.82\%) were HBsAg positive by ELISA. The mean seroprevalence of HBV from both ICT and ELISA was 2.60\%. The highest seroprevalence $(46.15 \%)$ was observed among the donor groups with age range of 21-30 years followed by (30.76\%) among 15-20 years, (15.38\%) among 31-40 years and the lowest seroprevalence $(7.69 \%)$ among $41-55$ years. Blood transfusion $(30.76 \%)$ was the most apparent influencing risk factor for HBV followed by dental treatment (23.07\%), Sexual partner positive for $\mathrm{HBV}$ infection $(15.38 \%)$, surgery and shave by the barbers $(7.69 \%)$ for each and unknown reason $(15.38 \%)$.

Keywords: Hepatitis B virus; ELISA; ICT; Risk factors; Blood donors

\section{Introduction}

Hepatitis B virus (HBV) is a minute, enclosed DNA virus identified in 1947 and was placed in family Hepadnaviridae and Genus Orthohepadna [1, 2]. It is a serious worldwide public health issue both in third world countries and developed countries [3]. About 2 billion individuals are infected with HBV globally, of which 400 million were chronic HBV carrier [4-6]. Every year approximately 1 to 2 million people die due to HBV-related diseases such as fibrosis, 
cirrhosis, chronic hepatitis, and hepatocellular carcinoma $[7,8]$. Some important ways for the transmission of HBV are the utilization of unsterilized medical instruments, blood transfusion, sharing of individual items, offering needles to drug addicts, barber risk, reuse of contaminated needles and syringes without sterilization for therapeutic injections, vertical transmission , furthermore by unsafe sexual interaction with HBV infected patients [9-12]. The prevalence of HBV infection among the developing countries of Asia, the Pacific Islands and Africa is very high as compared to developed countries like Australia, Western Europe, and the USA, where the prevalence of HBV is very low [13]. In Russia, Japan, and Eastern Europe about 2$8 \%$ of their population are infected with HBV. It is estimated by world health organization (WHO), that about 0.6 million deaths of the people occur annually due to HBV infection. As per 2010 report of WHO, it was observed that 0.12 billion individuals were infected with HBV in China followed by India with 0.04 billion and Indonesia with twelve million infected individuals [14]. In Pakistan, HBV is also a prominent public health issue, and its rate of infection is rising rapidly [15]. The reason for high infection rate might be due to deficiency of suitable public health services, poor financial condition or lack of awareness about the transmission of major sexually transmitted diseases (STDs) i.e. HBV, HCV, and HIV [16]. According to different research studies performed in the various regions of Pakistan, showed that the prevalence rate of $\mathrm{HBV}$ is 2$10 \%$ among healthy blood donors, 5-9\% among medical services staff, $3.16 \%$ among the pregnant women, 3.6-18.66\% among the general population, $10-20 \%$ of patients with temporary diagnosis of hepatitis and 3.16$10.4 \%$ among professional blood donors [17].
Blood donors, who are volunteers for blood donation, are usually considered as a healthier part of public community. All the blood banks in public and private hospitals have standard selection criteria for blood donation that helps to identify, and consequently only healthy donors are allowed to donate blood [18]. The percentage of HBsAg positive blood donors and risk factors associated with $\mathrm{HBsAg}$ positive situation among the healthy individuals may reflect the extent of $\mathrm{HBV}$ infection in the general population. Thus the current study was conducted to evaluate the prevalence and risk factors associated with $\mathrm{HBs} \mathrm{Ag}$ positivity among blood donors of district Charsadda, Khyber Pakhtunkhwa, Pakistan.

\section{Materials and methods Study design and sample collection}

This retrospective study was conducted at the Department of Pathology, Hayatabad Medical Complex (HMC), Peshawar, from $3^{\text {rd }}$ September 2015 to $30^{\text {th }}$ August 2016. A total of 460 blood samples were collected from volunteer blood donors of district Charsadda and tested for hepatitis B surface antigen (HBsAg). Risk factors were evaluated carefully, and detailed medical history of each blood donor was recorded on structured questioner (Performa) and consent form. All the blood donors included in the study were male with age range 15-55 years. About $5 \mathrm{~mL}$ blood sample was collected from each blood donor with a disposable syringe under aseptic conditions and allowed to clot. Serum was separated from each blood sample in a centrifuge machine at $4000 \mathrm{rpm}$ for 5 minutes and was transferred to sterilized test tubes for further qualitative and quantitative screening tests. The initial qualitative tests were carried out by chromatographic immunoassay (Acon, USA) for the detection of HBsAg in blood serum. All the positive and negative samples on ICT were further screened on $3^{\text {rd }}$ Generation ELISA Technique (EASE BN-96 TMB, Taiwan) to evaluate the 
specificity and sensitivity of ICT and ELISA assays.

Detection of hepatitis B surface antigen (HBsAg) by ICT

We used ICT strips (Acon, USA) according to maker's instructions for the detection of HBsAg. The test strip was removed from the foil pouch and was kept on a clean, dry surface. Then $100 \mu \mathrm{L}$ serum sample was dispensed in the strip. After 15 minutes, the results were interpreted according to the appearance of color bands. The control was also run to check the validity of the strip. Both purplish red test bands and purplish red control band appeared on the membrane of the strip which showed a positive result. One red line appears in the layer of the strip in the control region (C). The appearance of no red line in the test area indicated a negative result [19].

\section{Detection of hepatitis B surface antigen (HBsAg) by ELISA}

All the positive and negative samples on ICT were further screened on third generation ELISA (EASE BN-96 TMB, Taiwan) according to maker's instructions. Three wells covered with anti-HBs were taken and placed in a holder. $50 \mu \mathrm{L}$ of the positive control, negative control and specimens were added to their respective wells. Then $50 \mu \mathrm{L}$ of HRP-conjugate was added to each well except the blank and were mixed by tapping the plate gently. Covered the plate with glue slip and was incubated at $37^{\circ} \mathrm{C}$ for one hour. After incubation, the glue slip was removed from each well and washed five times with diluted buffer. $50 \mu \mathrm{L}$ of chromogen solution A and $50 \mu \mathrm{L}$ of chromogen solution B were dispensed into each well including the blank and were mixed by tapping the plate gently for 15 seconds. The plate was then incubated at $37^{\circ} \mathrm{C}$ in the dark for 15 minutes without shaking. $50 \mu \mathrm{L}$ of Stop solution was added to stop the reaction. The absorbance of controls and specimens were determined within 15 minutes by spectrophotometer. The enzymatic reaction between the chromogen solutions and HRP-conjugate produced a blue color in positive control well and HBsAg positive sample wells before the addition of stop solution. After addition of stop solution, the blue color in positive control well and HBsAg positive wells changed to yellow color; Negative samples have clear water like appearance before and after addition of stop solution. Absorbance values of Specimen equal to or greater than the cut-off value i.e. (2.00) were considered HBsAg positive and Specimen with absorbance values less than the cut-off value were considered HBsAg negative [20].

\section{Results}

A total of 460 male blood donors with age range 15-55 years were tested for HBsAg by Immunochromatographic technique (ICT) and $\quad 3^{\text {rd }}$ generation enzyme-linked immunosorbent assay (ELISA). Out of 460 blood samples, 11(2.39\%) were found positive for HBsAg by ICT, and $13(2.82 \%)$ by ELISA. The mean seroprevalence of HBV from both ICT and ELISA was (2.60\%), (Table 1). The highest seroprevalence (46.15\%) was found among participants within the age range of 21-30 years followed by $(30.76 \%)$ among $15-20$ years, (15.38\%) among 31-40 years and lowest seroprevalence $(7.69 \%)$ among $41-55$ years (Figure 1). Blood transfusion (30.76\%) was the most apparent influencing risk factor for HBV followed by dental treatment (23.07\%), Sexual partner positive for $\mathrm{HBV}$ infection $(15.38 \%)$, surgery and shave by the barbers $(7.69 \%)$ for each and unknown reason (15.38\%) (Figure 2). 
Table 1. Frequency distribution and percentages of HBV by ICT and ELISA among blood donors of district Charsadda, KP, Pakistan

\begin{tabular}{|l|c|c|c|c|}
\hline Parameters & $\begin{array}{l}\text { Total Number } \\
\text { of samples }\end{array}$ & $\begin{array}{l}\text { Total Negative } \\
\text { Samples }\end{array}$ & $\begin{array}{l}\text { Total Positive } \\
\text { Samples }\end{array}$ & $\begin{array}{l}\text { Positive } \\
\text { Percentage }\end{array}$ \\
\hline HBsAg by ICT & 460 & 449 & 11 & $2.39 \%$ \\
\hline HBsAg by ELISA & 460 & 447 & 13 & $2.82 \%$ \\
\hline $\begin{array}{l}\text { Mean Seroprevalence } \\
\text { by ICT \& ELISA }\end{array}$ & 460 & 448 & 12 & $2.60 \%$ \\
\hline
\end{tabular}

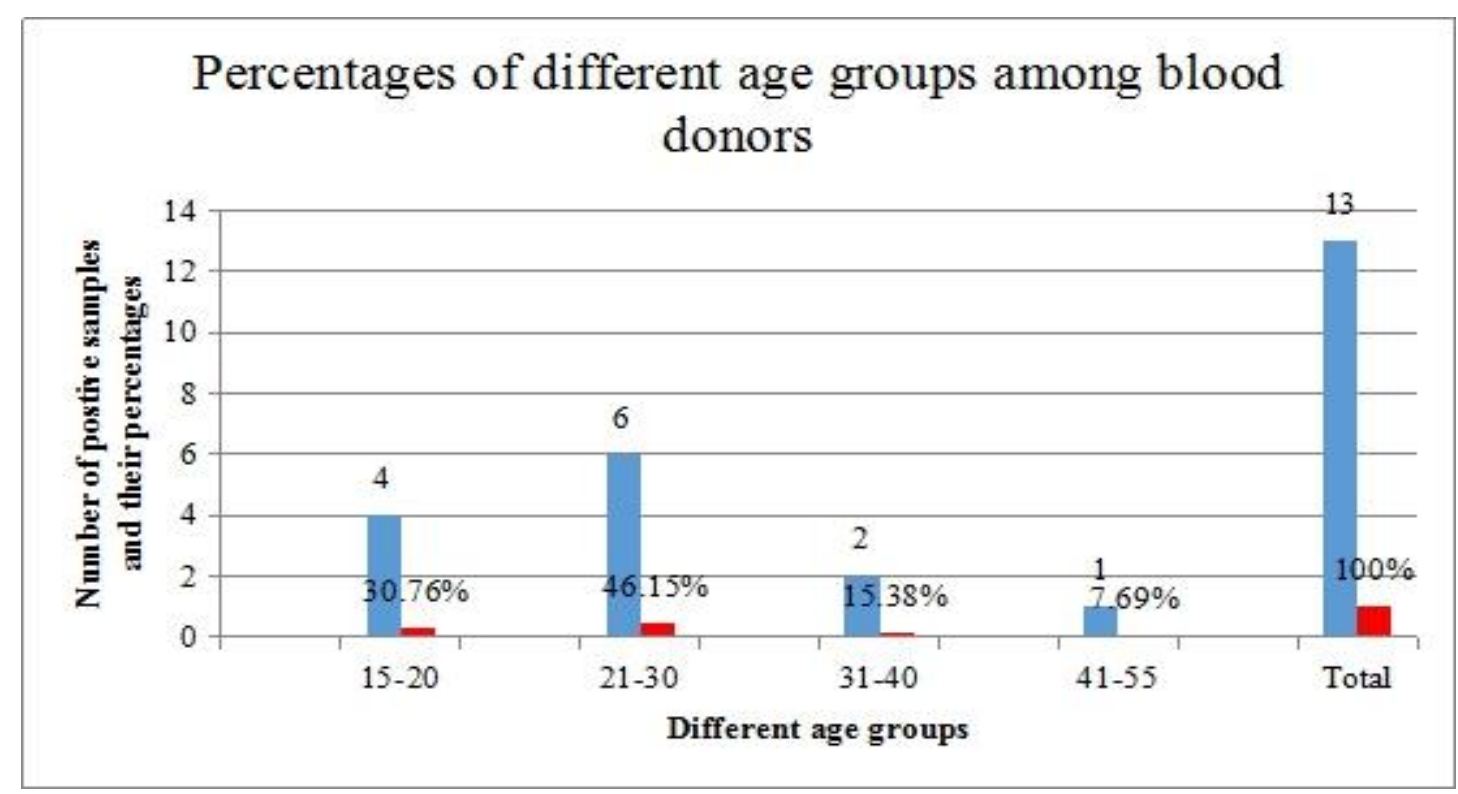

Figure 1. Percentages of the different age groups of blood donors from district Charsadda, KP Pakistan. The blue color in the figure showed positive samples and red color showed the positive percentage of different age groups

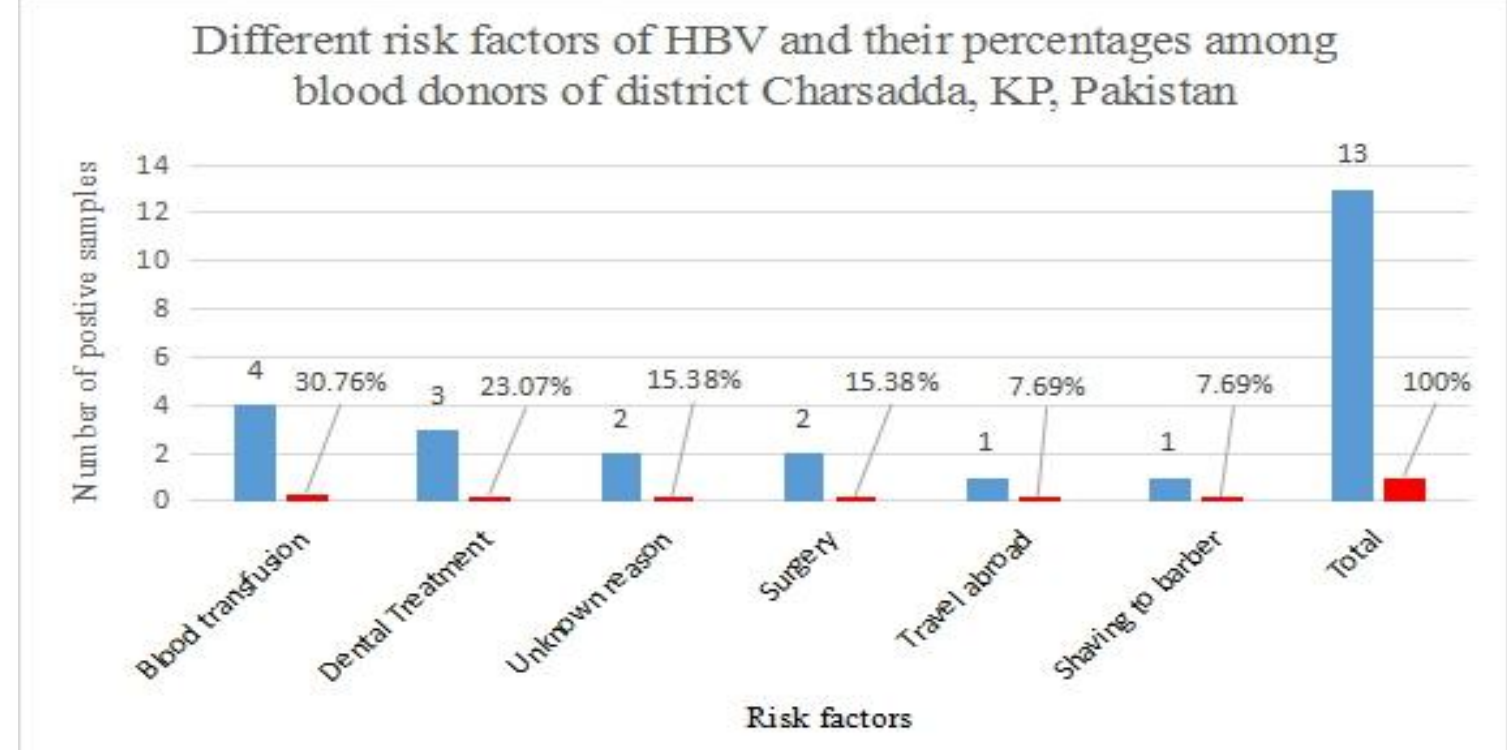

Figure 2. Different risk factors of HBV and their percentages among blood donors of district Charsadda, KP, Pakistan 


\section{Discussion}

The purpose of the current study was to investigate the seroprevalence of $\mathrm{HBV}$ infection and its possible risk factors associated with HBsAg positivity through ICT and $3^{\text {rd }}$ generation ELISA among healthy blood donors of district Charsadda, Khyber Pakhtunkhwa Pakistan. All the blood donors included in this study were males because the majority of females in Pakistan do not donate blood due to traditions, especially in Khyber Pakhtunkhwa. The seroprevalence of HBV in our study was $(2.60 \%)$ which was quite similar to the prevalence of $\mathrm{HBV}$ among blood donors in Peshawar (2.68\%) [21] and Bahawalpur (2.69\%) [22].While it was lower than the prevalence reported from some other regions of the country including $(6.2 \%)$ in Interior Sindh [22], (5.86\%) in Rawalpindi [23] and $(5.81 \%)$ in Thatta [24].Where it was higher when compared with data reported from some other cities of the country including Lahore (1.52\%) [25] and Abbottabad (1.55\%) [26].

Overall $2.60 \%$ prevalence of HBV indicated that Charsadda falls into the intermediate range of HBV infective region of the country. The low prevalence of HBV infection might be due to public awareness, adopting the sensitive techniques like ELISA for screening and implementation of strict standard criteria for blood donor's deferral in the case of possible risk factors.

Our results indicated that ICT used for detection of HBsAg was less sensitive as compared to ELISA because two additional samples were detected by ELISA (Table 1). This might be due to the short incubation period of ICT because characteristically short incubation tests do not detect low concentration of HBsAg in the serum. Therefore the probability of false negative results in a nutshell incubation test i.e. ICT is higher than that of ELISA using longer incubation periods and multiple antigens.It was observed in our study that ELISA
Method is more specific and sensitive than ICT for routine screening of blood donors. The similar results were also reported by Khan et al. [27], Abdelbagi et al. [28] and Mustafa et al.[29].

In this study, risk factors associated with HBV were evaluated by a detailed medical history of each blood donor, recorded by the structured questioner (Performa) and consent form. Blood transfusion $(30.76 \%)$ was the most deceptive influencing risk factor for HBV active blood donors followed by dental treatment $(23.07 \%)$, Sexual partner positive for $\mathrm{HBV}$ infection (15.38\%), surgery and shave by the barbers $(7.69 \%)$ for each and unknown reason $(15.38 \%)$. These results were supported by other study conducted in Abbottabad which revealed the different risk factors; blood transfusion of hepatitis B positive individuals was $32(91.4 \%)$, dental treatment was $(21 \quad(60 \%)$ and surgical procedure was $12(34.28 \%)$ [30].

\section{Conclusion}

In this study we found $2.60 \%$ seroprevalence of HBV among blood donors from district Charsadda, Khyber Pakhtunkhwa, Pakistan. The highest seroprevalence $(46.15 \%)$ was among the age group of 21-30 years, while the lowest seroprevalence $(7.69 \%)$ was among the age group of 41-55 years. Blood transfusion $(30.76 \%)$ was the most apparent influencing risk factor for $\mathrm{HBV}$, while surgery $(7.69 \%)$ and shave by the barber (7.69\%) were the lowest risk factors. It was concluded that ELISA is more specific and sensitive method than ICT for routine screening of blood donors.

\section{Recommendations}

Awareness regarding control measures in health-care settings including proper sterilization techniques of medical instruments and to educate barbers about the significance of sterilization of their instruments might reduce the problem of HBV infection in this and similar settings. 
There is also an urgent need to increase relevant guidelines for counseling and management of $\mathrm{HBs}$ Ag-positive blood donors.

It is necessary to implement the strict standard selection criteria to defer and discourage the blood donors with certain high-risk factors. Vaccination for HBV should be adopted at national level. ELISA assay should be adopted in routine blood screening to prevent the transmission of HBV infection and to ensure the safe blood transfusion

\section{Authors' contributions}

Conceived and designed the experiments: $M$ Israr \& F Ali, Performed the Experiments: M Israr, F Ali \& N Bahadar, Analyzed the Data: $\mathrm{M}$ Israr, $\mathrm{N}$ Bahadar \& $\mathrm{M}$ Muhammad, Contributed reagents/ materials/ analysis tools: M Israr, N Bahadar \& M Muhammad, Wrote the paper: M Israr.

\section{Acknowledgment}

The authors are thankful to Professor Dr. Shahtaj Khan and Mr. Aslam Khan (Department of Pathology, HMC, Peshawar) for their constructive suggestions and guidance. We are also thankful to Mr. Izhar Allah to provide proper guidance during research work.

\section{References}

1. Seeger C \& Mason WS (2000). Hepatitis B virus biology. Microbiol Mol Biol 64: 51-68.

2. Purcell RH (1993). The discovery of the hepatitis viruses. Gastroenterology 104: 955-63.

3. Fiore A \& Neeman R (2004).Viral hepatitis transmission. Clin Inf 38: 15081592.

4. Zhu CT \& Dong CL (2009). Characteristics of general distribution of hepatitis B virus genotypes in China. Hepatob Pancreat Dis 8: 397-401.

5. Paraskevis D, Haida C, Tassopoulos N, Raptopoulou M, Tsantoulas D, Papachristou H, Sypsa V \& Hatzakis A
(2002). Development and assessment of a novel real-time PCR assay for quantitation of HBV DNA. J Virol Meth 103: 201-212.

6. Jose AMM, Carla LAA, Gloria MC, Sergio CR, Jose LFA, Rafael AF \& Jesus GM (2012). Prevalence and resistance pattern of genotype $\mathrm{G}$ and $\mathrm{H}$ in chronic hepatitis B and HIV co-infected patients in Mexico. Annal Hepatol 11: 47-51.

7. Khan F, Akbar H, Idrees M, Khan H, Shahzad K \& Kayani MA (2011a). The prevalence of HBV infection in the cohort of IDPs of war against terrorism in Malakand Division of Northern Pakistan. BMC Infect 11: 176.

8. Mahoney FJ (1999). Update on diagnosis, management, and prevention of hepatitis B virus infection. Clin Microbiol Rev 12: 351-366.

9. Bukhari SM, Khatoon N, Iqbal A, Naeem S, Shafqat S, Lone A \& Naveed IA (1999). Prevalence of hepatitis B antigenaemia in Mayo hospital Lahore. Biomedica 15: 8891.

10. Fairley CK \& Read TR (2012). Vaccination against sexually transmitted infections. Curr Opin Infect Dis 25(1): 66-72.

11. Buddeberg F, Schimmer BB \& Spahn DR (2008). Transfusion-transmissible infections and transfusion-related immunomodulation. Best Pract Res $\mathrm{Cl}$ An 22(3): 503-17.

12. Hughes RA (2000). Drug injectors and the cleaning of needles and syringes. Eur Addict Res 6: 20-30.

13. Khan NU, Siddique L, Ali I, Iqbal A, Munir I \& Rashid F (2010). Prevalence of hepatitis B in the blood donors of NW.F.P and FATA regions and the current scenario of HBV infection in Pakistan. Afr J Biotechnol 9: 6162-6166.

14. The Jakarta Post (2011). Healthcare stumbling in RI's hepatitis fight.

15. Awan Z, Idrees M, Amin I, Butt S, Afzal S, Akbar H, Rehman I, Younas S, Shahid 
M, Lal A, Saleem S \& Rauff B (2010). Pattern and molecular epidemiology of hepatitis B virus genotypes circulating in Pakistan. Infect Gen Evol 10: 1242-1246.

16. Alam MM, Zaidi SZ, Malik SA, Shaukat S, Naeem A, Sharif S, Angez M \& Butt JA (2007b). Molecular epidemiology of hepatitis B virus genotypes in Pakistan. BMC Infect 7: 115.

17. Alam MM, Zaidi SZ, Shaukat S \& Sharif S (2007). Common Genotype of hepatitis B Virus prevalent in injecting drug (addicts) of North West Frontier Province of Pakistan. Virol J 4: 63.

18. Pillonel J, Saura C \& Courouce AM (1998). Prevalence of HIV, HTLV, and hepatitis $\mathrm{B}$ and $\mathrm{C}$ viruses in blood donors in France, 1992-1996. Transfus Clin Biol 5: 305-312.

19. Lau DTY, Ma H, Lemon SM, Doo M, Ghany MG, Miskovsky E, Woods GL, Park Y \& Hoofnagle JH (2003). A rapid immunochromatographic assay for hepatitis B virus screening. J Viral Hepatitis 10(4): 331-334.

20. Khattak MF, Salamat N, Bhatti FA \& Qureshi TZ (2002). Seroprevalence of hepatitis B, C and HIV in Blood Donors in Northern Pakistan. JPMA 52: 398.

21. Attaullah S, Khan S \& Khan J (2012). Trend of transfusion transmitted infections frequency in blood donors: provide a road map for its prevention and control. J Transl Med 10(1): 20.

22. Fayyaz M, Khan MA, Chaudhary GM, Qazi MA \& Ahmed G (2006). Hepatitis $\mathrm{B}, \mathrm{C} \& \mathrm{HIV}$, seroprevalence of infection in blood donors. Prof Med J 13(4): 63236.

23. Mujeeb SA \& Pearce MS (2008). Temporal trends in hepatitis $\mathrm{B}$ and $\mathrm{C}$ infection in family blood donors from interior Sindh, Pakistan. BMC Infect Dis 8: 43.
24. Mumtaz S, Rehman M, Muzaffar M, Hassan M \& Iqbal W (2002). Frequency of seropositive blood donors for hepatitis $\mathrm{B}, \mathrm{C}$ and HIV viruses in railway hospital Rawalpindi. Pak J Med Res 41: 51-3.

25. Ishaq M, Ali SS, Karim N, Umrani NI \& Hassan N (2007). Frequency of hepatitis $\mathrm{B}$ and $\mathrm{C}$ virus among the healthy volunteer blood donors at Taulka hospital Sujjawal, District Thatta, Sindh. Ann Abbasi Shaheed Hosp Karachi Med Dent Coll 12: 97-101.

26. Fayyaz KM, Ali S, Khan AA, Shafique M, Khan MA, Majeed S \& Butt AS (2002). Hepatitis B carriers; diagnosis among volunteer blood donor students at Quaid i-Azam medical college Bahawalpur. Professional Med J 9: 18690.

27. Khan JK, Lone A, Hameed MR, Munim M, Bhatti AA, Khattak M, Usman MF, Nadeem HS, Satti \& Munir M (2010). Evaluation of the Performance of Two Rapid Immunochromatographic Tests for Detection of hepatitis B Surface Antigen and Anti HCV Antibodies Using Elisa Tested Samples. Sp Ed Ann 16: 1.

28. Abdelbagi M, Hadya N, Tayeb A \& Ahmad M (2007). Seroprevalence of hepatitis B and C Viral Infections among Blood Donors in Shendi, River Nile State, Sudan. Res J Med Med Sci 2(2): 122-126.

29. Mustafa AA, Yassir ME \& Ali AS (2009). Seroprevalence of hepatitis B virus and Hepatitis $C$ virus among blood donors in Nyala, South Dar Fur, Sudan. Virol J 6: 146.

30. Rehman FU, Jehangir K, Zahid F, Arshad P, Ahmad R \& Shandana S (2011). Identifiable Risk Factors In Hepatitis B And C. J Ayub Med Coll Abbottabad 23(4). 